\title{
INTEGRAÇÃO DA FERRAMENTA MULTIPROVA AO SISTEMA INTEGRADO DE GESTÃO DE ATIVIDADES ACADÊMICAS
}

\author{
Gibeon Soares de Aquino Júnior, DIMAP - UFRN, gibeon@dimap.ufrn.br \\ Diego Rodrigo Cabral Silva, ECT - UFRN, diego@ect.ufrn.br \\ Andre Bessa Moreira, ECT - UFRN, abessa@ect.ufrn.br \\ Allan De Medeiros Martins, DEE - UFRN, allan@dca.ufrn.br
}

\begin{abstract}
Resumo. Este artigo descreve a iniciativa de integração entre dois sistemas de software no contexto acadêmico de uma universidade federal. Os sistemas envolvidos nessa ação são: o SIGAA, que é um sistema de informação web institucional que informatiza diversos procedimentos da área acadêmica, e o Multiprova, que é uma ferramenta que permite ao docente gerar, de forma controlada, variações nos aspectos acessórios do enunciado e das alternativas das questões. Esta iniciativa tem como propósito contribuir com o processo de ensino-aprendizagem, através do uso de tecnologia, ajudando a vencer desafios, como o gerenciamento de turmas grandes e geração de feedbacks rápidos de aprendizagem aos discentes e docentes.
\end{abstract}

Palavras-chaves: integração de sistemas, geração de provas, sistema acadêmico.

\section{MULTIPROVA TOOL INTEGRATION TO THE SIGAA - INTEGRATED MANAGEMENT SYSTEM OF ACADEMIC ACTIVITIES}

\begin{abstract}
This paper describes the integration initiative of two software systems in the context of a brazilian federal university. The systems involved in this work are: SIGAA, a web information system that supports several academic procedures in the university, and the Multiprova, which is a tool that allows the teacher to generate variations of some aspects in the question statement and its answer alternatives. This initiative aims at contributing to the process of teaching and learning through the use of technology, helping to overcome challenges such as managing large classes and generating quick feedback learning to students and teachers.
\end{abstract}

Keywords: system integration, exams generation, academic system.

\section{Introdução}

Vivemos hoje um momento de oportunidades no Ensino Superior. A facilidade do acesso não garante, porém, o sucesso da formação. As novas tecnologias vêm desempenhando um papel cada vez mais central na tarefa de aprimorar a vivência acadêmica. Em uma grande instituição como é uma universidade, a todo instante, diferentes iniciativas voltadas ao ensino são experimentadas, de forma independente, em 
seus contextos locais. Quando uma ferramenta se mostra promissora para a comunidade, é natural que se proponha a extensão de seus benefícios a um grupo maior de usuários. Os desafios envolvidos nessa expansão, no caso concreto do software Multiprova e sua relação com o SIGAA, são o objeto central deste trabalho.

O artigo tem a seguinte estrutura: na Seção 2 trazemos o histórico e as funcionalidades do SIGAA; a Seção 3 é dedicada ao Multiprova, sendo que sua última subseção descreve um eficiente método de correção instantânea de avaliações por meio de aparelhos celulares. Na Seção 4, discutimos a integração entre os dois sistemas; os resultados esperados dessa integração estão na Seção 5. Finalmente, apresentamos as considerações finais na Secão 6.

\section{O SIGAA}

O SIGAA (Sistema Integrado de Gestão de Atividades Acadêmicas) é um sistema de informação web corporativo que informatiza diversos procedimentos da área acadêmica na UFRN. Ele foi criado em 2006 e desde então é usado por todos os discentes, docentes e servidores técnico-administrativos que apoiam as atividades de ensino. Além disso, a partir de 2009 ele começou a ser usado em outras universidades federais brasileiras através de convênios de cooperação, que deram início ao que atualmente é chamado de Rede de Cooperação IFES ${ }^{1}$. Atualmente, aproximadamente dezenove instituições federais fazem parte desta rede.

Em função desse sucesso, o sistema tem crescido bastante desde sua criação, abrangendo a informatização de muitos procedimentos acadêmicos. Atualmente, ele possui aproximadamente 1.900 funcionalidades, organizadas em diversos módulos, como pode ser visto na Figura 1. Em termos de pontos de função, medida de tamanho funcional padrão da indústria de software (Albrecht, 1979; ISO, 2009), o SIGAA possui 22.369. Essa contagem foi realizada de acordo com o método de contagem NESMA (ISO, 2005). Do ponto de vista de implementação, ele possui 646.382 linhas de código, 4.750 classes e 1.135 tabelas contidas em 40 esquemas.

As funcionalidades do sistema abrangem a graduação, pós-graduação (stricto e lato sensu), ensino técnico, ensino médio e infantil, submissão e controle de projetos e bolsistas de pesquisa, submissão e controle de ações de extensão, submissão e controle dos projetos de ensino (monitoria e inovações), registro e relatórios da produção acadêmica dos docentes, atividades de ensino a distância e um ambiente virtual de aprendizado denominado Turma Virtual. Este módulo é um dos mais usados, que é o espaço onde ocorre a interação entre o docente e o discente. Seu objetivo é melhorar o processo de ensino-aprendizagem, criando uma extensão da sala de aula através de um ambiente virtual.

\section{A Ferramenta Multiprova}

A ferramenta Multiprova tem como objetivo disciplinar o estudo dos alunos com avaliações periódicas que sejam individualizadas e que forneçam informações rápidas e organizadas sobre o andamento do processo de ensino-aprendizagem para alunos, professores e gestores.

\footnotetext{
${ }^{1}$ http://www.portalcooperacao.info.ufrn.br/
} 


\subsection{Histórico e Motivação}

Nos últimos anos, as oportunidades e a procura pela formação superior aumentaram de modo significativo, seja nas instituições de ensino público, seja nas de ensino privado (Speller et al, 2012). A adequação dos cursos à chegada desse grande contingente de novos estudantes não seguiu um modelo centralizado, mas ficou a cargo de cada instituição. Na Escola de Ciências e Tecnologia da UFRN, por exemplo, as turmas têm, em média, mais de cem alunos, sendo que muitas delas começam com cento e quarenta estudantes. A adoção de turmas grandes é a estratégia mais econômica para acomodar a expansão da oferta de vagas. Se, por um lado, este modelo parece ser mais eficiente - na medida em que o investimento na formação de um professor-doutor é compartilhado por centenas de estudantes, por outro lado, os desafios que as turmas grandes representam para o processo de ensino-aprendizagem constituem um grande obstáculo para a qualidade da formação. O desafio é fazer inclusão com qualidade.

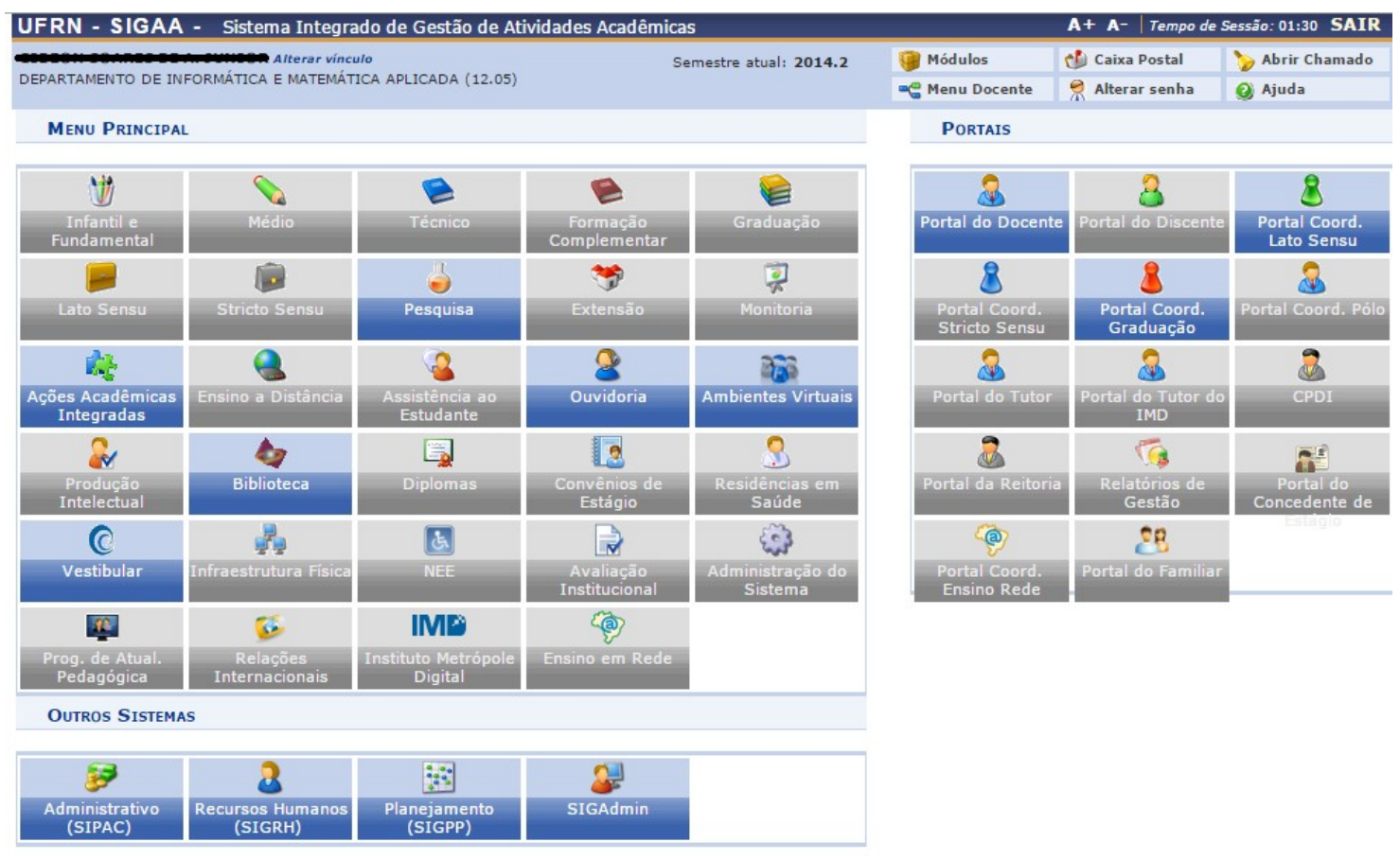

Figura 1 - Módulos funcionais do SIGAA

Fosse a cultura do estudante brasileiro mais autônoma, fazer parte de uma turma grande não seria um problema. A tendência em vários países é a redução do número de horas presenciais de estudo, estimulando-se as atividades à distância baseadas em conteúdos digitais (Altbach et al, 2009). No Brasil, temos observado que o estudante condiciona o sucesso de seu curso à existência de uma estrutura de apoio que o motive a estudar, que o leve a superar as deficiências de sua formação, como se não fosse ele o protagonista de seu próprio processo de ensino-aprendizagem (Gil, 2011). Não cabe aqui discutirmos as causas que levaram os estudantes a este comportamento passivo, mas o que podemos fazer em termos de estratégias didáticas para fazê-los progredir.

Um professor que ministra aulas em uma turma com cerca de cem alunos não pode adotar uma série de iniciativas sob pena de comprometer todas as suas demais atividades acadêmicas. Nessas circunstâncias, como estar a par do progresso dos estudantes, obtendo e fornecendo informações sobre o andamento de seus estudos? Não há dúvida de que, qualquer que seja a estratégia utilizada para avançar nessa 
problemática, as ferramentas tecnológicas terão um papel central. Foi nesse contexto que surgiu o Multiprova.

\subsection{Funcionalidades}

Quando se elabora uma questão, existem aspectos essenciais -- o que se deseja avaliar, e aspectos acessórios, não-essenciais. Por exemplo, na pergunta: "Quantos mols correspondem a 9,2 kg de dióxido de carbono $\left(\mathrm{CO}_{2}\right)$ ?", o essencial é o estudante saber calcular o número de mols a partir da massa molecular do $\mathrm{CO}_{2}$. O valor "9,2 kg" é nãoessencial, na medida em que uma alteração neste valor não vai mudar em nada o raciocínio ou a dificuldade da questão. Por outro lado, a variação da molécula de $\mathrm{CO}_{2}$ para $\mathrm{C}_{6} \mathrm{H}_{12} \mathrm{O}_{6}$ não altera o raciocínio, mas complica os cálculos. Porém, se a mudança fosse de $\mathrm{CO}_{2}$ para $\mathrm{NO}_{2}$ ou $\mathrm{SO}_{2}$, a questão seria essencialmente a mesma.

O que a ferramenta Multiprova faz é permitir que o professor gere, de forma controlada, variações nos aspectos acessórios do enunciado e das alternativas das questões de modo que, a partir de uma única matriz de questão, uma enorme quantidade de questões diferentes, porém essencialmente equivalentes, sejam criadas. Aspectos acessórios podem ser números, palavras, fórmulas, gráficos ou imagens. Para gerá-los, o professor dispõe de variáveis aleatórias e funções de simples gerenciamento. O conceito de equivalência entre questões se estende também a provas: se $\mathrm{N}$ provas são consideradas equivalentes, o aplicativo escolhe, aleatoriamente, uma das $\mathrm{N}$ provas para cada estudante. Essas características distinguem o Multiprova de outras ferramentas computacionais de avaliação como o NetAula (Kampff e Alves, 2010).

Multiprova é compatível com a linguagem Latex de preparação de textos matemáticos de alta qualidade. Isso permite variar as quantidades nas fórmulas, matrizes, tabelas ou gerar gráficos individualizados em 2 ou 3 dimensões, como ilustra a Figura 2. É possível também colocar imagens nas questões. Para facilitar o gerenciamento de questões e o acompanhamento do desempenho dos estudantes, o professor pode associar a elas rótulos (tags).

A quantidade de alternativas é arbitrária. É possível colocar alternativas erradas do tipo "pegadinha", com resultados que se obtém por caminhos conceitualmente incorretos. Após a aplicação da avaliação, o professor tem acesso às estatísticas de marcação das respostas certas e de cada pegadinha colocada, além de muitas outras informações, como histograma de notas, média, desvio padrão e acertos por questão.

A correção pode ser feita por leitura ótica de cartão resposta. Utilizando-se um scanner comercial de baixo custo consegue-se corrigir mais de 35 provas por minuto. Assim, instantes após a aplicação da avaliação, professores e alunos têm acesso a várias informações organizadas. Elas podem ser usadas para realimentar o processo de ensinoaprendizagem, permitindo que o professor intervenha de forma eficiente no aprendizado da turma. O sistema envia feedback também para os alunos: além das notas nas avaliações, a associação de rótulos (tags) às questões permite acompanhar o histórico de cada estudante, transversalmente às disciplinas. Por exemplo, o Multiprova pode manter o aluno informado acerca de sua taxa de acertos nas questões que envolvem gráficos, seja na disciplina de Química, de Termodinâmica, etc. A proposta é que, com base nesses históricos, planos de estudo possam ser enviados aos estudantes para suprir deficiências ou potencializar competências adquiridas.

Todos os recursos mencionados permitem que o professor construa rapidamente um banco de questões e provas com enorme variabilidade. Atualmente, as avaliações estão disponíveis apenas na versão em papel. Em uma futura versão web, será possível 
liberar os estudantes de se submeterem todos à avaliação simultaneamente: o professor poderá dar um prazo para que os alunos estudem e realizem, a seu tempo, a avaliação em uma sala com dispositivos onde o Multiprova esteja disponível.

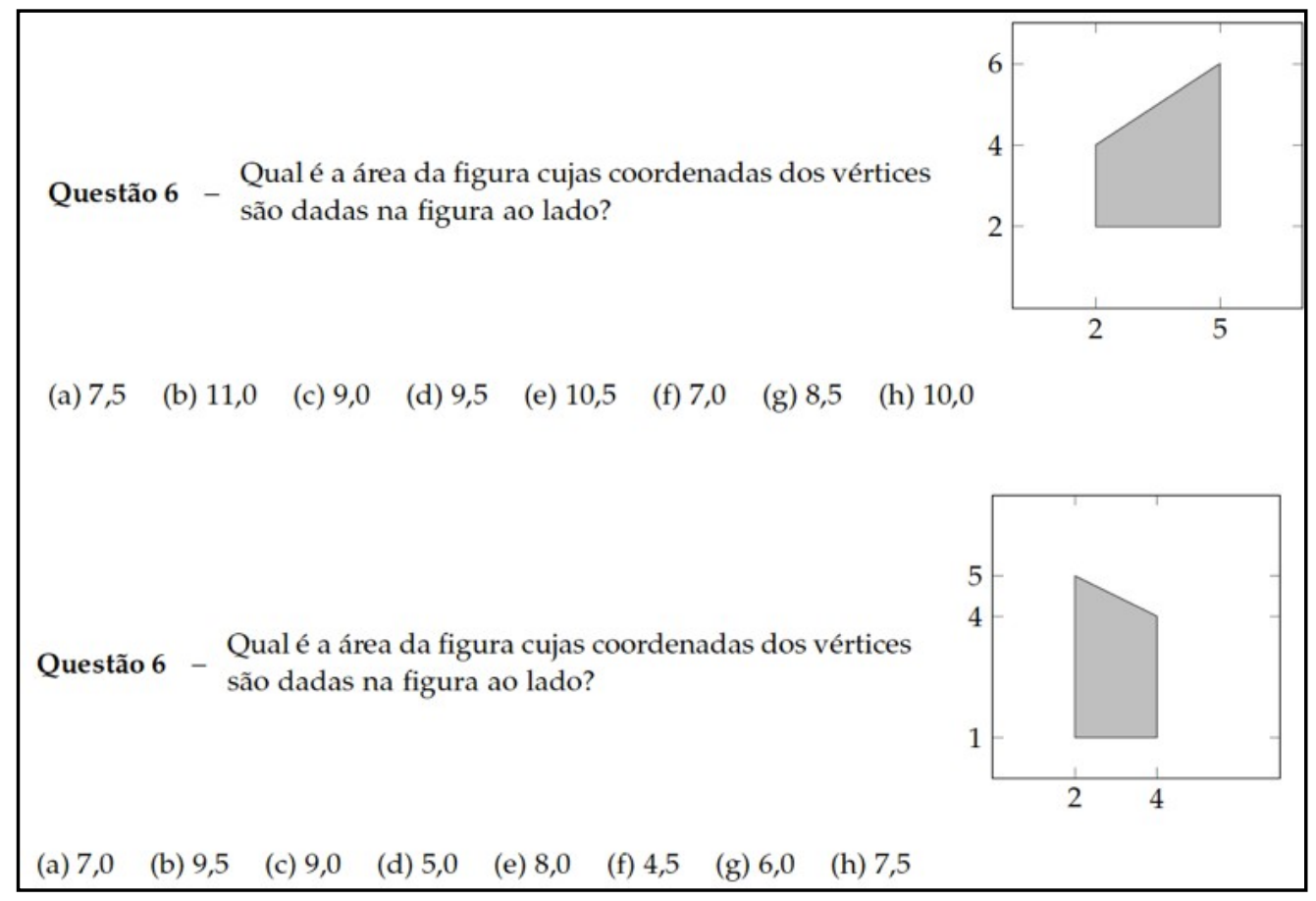

Figura 2. Exemplo de variações de uma questão gerada com Multiprova.

Existe ainda uma ferramenta que possibilita a correção da prova utilizando-se um aplicativo para smartphone. Nesta opção, o aluno preenche um gabarito com o formato pré-determinado. Neste gabarito existem três espaços reservados para preenchimento da matrícula do aluno, identificação da prova e respostas. A Figura 3 mostra dois exemplos de tela da aplicação durante o processo de correção pelo smartphone.

O gabarito possui ainda quatro marcações padrão (pequenas cruzes) que servem de base para o algoritmo de reconhecimento de imagem do aplicativo. Após preenchimento do gabarito com a matrícula e respostas das questões, a correção é feita pelo aplicativo. $\mathrm{O}$ aplicativo retira uma foto do gabarito, que deve ser enquadrado, de modo que os marcadores em cruz fiquem próximos aos cantos da foto. Retirada a foto, o aplicativo executa o algoritmo de processamento de imagens que irá reconhecer automaticamente a matrícula do aluno, tipo de prova e respostas.

Os benefícios gerados pela correção automática são evidentes para o aluno, que tem sua nota imediatamente disponibilizada. A possibilidade de correção instantânea, também tem a vantagem de prover retorno imediato, ao professor, de atividades realizadas em sala de aula. Como mencionado anteriormente, esta capacidade de avaliação imediata pode guiar a dinâmica de uma aula, possibilitando ao professor focar nos conteúdos onde a turma esteja apresentando maior necessidade.

\subsection{Resultados alcançados}

Atualmente, cerca de 10 professores utilizam a ferramenta Multiprova nas turmas da ECT/UFRN. Apenas no segundo semestre de 2014, mais de 6000 avaliações individuais foram aplicadas em disciplinas de Matemática, Física e Informática. Diferentes metodologias estão sendo experimentadas. De forma geral, os efeitos observados do uso de testes regulares como instrumentos de avaliação continuada são os seguintes: maior 
organização do estudo dos alunos; diluição do peso da avaliação somativa ao final da unidade; maior convergência entre as ações do professor e as necessidades dos alunos. Pesquisas qualitativas indicam que, para a grande maioria dos alunos, a ferramenta funciona como um recurso auxiliar importante para o bom andamento dos estudos, contribuindo para reduzir os índices de reprovação. Para os professores, os testes representam um instrumento eficiente para disciplinar o estudo dos alunos e verificar rapidamente o sucesso de estratégias didáticas, sem comprometer suas demais atividades acadêmicas.
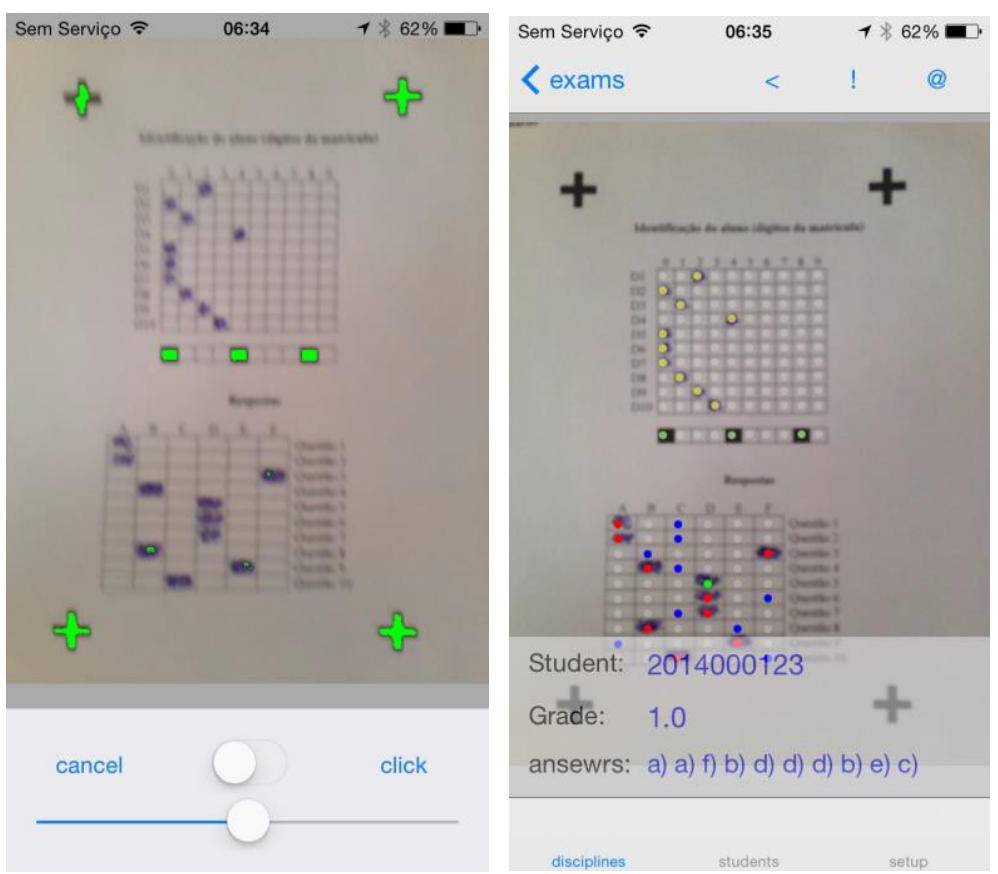

Figura 3. Telas do aplicativo referentes ao sistema de correção automática.

O sistema de correção através de smartphone utilizando o aplicativo vem sendo utilizado desde o primeiro semestre de 2012 em diversas disciplinas, como Sistemas de Controle I e Controle Digital, do curso de Engenharia Elétrica. Ao todo, foram 6 semestres em um total de 48 provas. Nas disciplinas onde o sistema foi utilizado, com uma média de 30 alunos por disciplina, totalizam-se cerca de 1440 gabaritos corrigidos até o momento. É importante ressaltar que, embora o sistema não tenha apresentado nenhum erro de reconhecimento, existem em média 2 casos de preenchimento errado da matricula por avaliação. Nestes casos, apesar de o professor ser capaz de ver a nota do aluno imediatamente, o sistema não tem como enviar a nota para o aluno devido ao preenchimento incorreto por parte do aluno.

\section{Integração do Multiprova com o SIGAA}

Como visto nas Seções 3 e 4, ambos os sistemas são de extremo valor para as atividades acadêmicas desempenhadas pela instituição. O SIGAA já está institucionalizado e apoia a execução de inúmeros procedimentos acadêmicos, fazendo parte do dia-a-dia de todos os discentes e docentes da instituição. O Multiprova, por sua vez, vem se mostrando extremamente útil no processo de ensino-aprendizagem, apoiando de maneira muito eficiente as atividades de ensino e avaliação de alunos. A cooperação entre estes dois sistemas trará diversos benefícios para a universidade, criando um ambiente ainda mais rico de apoio aos processos de ensino. 


\subsection{Motivação}

Existem alguns conceitos no Multiprova que manipulam dados da instituição utilizadora, como usuários, turmas, disciplinas, alunos e, principalmente, notas. Hoje, tais informações são copiadas manualmente entre os sistemas, em uma via de mão dupla. Esta solução traz muitos inconvenientes e trabalho extra ao se utilizar dois sistemas não integrados entre si. Por exemplo, a criação de turmas no Multiprova (simplesmente para a representação da entidade real, já que o mesmo não tem o objetivo de gerenciar turmas) cria duplicidade e desalinhamento de informações sempre que um aluno tranca a disciplina ou entra na turma pela última chamada do SISU. O cálculo de notas, com pesos para cada atividade, também é afetado, tendo que ser feito manualmente e depois inserido no SIGAA.

Felizmente, todos esses inconvenientes podem ser resolvidos quando há interesse de ambas as partes. Um projeto integrador, onde seriam definidas as interfaces de comunicação e troca de informações, seria uma maneira de o Multiprova consultar informações do banco de dados da instituição utilizadora sem duplicidade e com muito mais segurança e sincronia.

Após a integração dos sistemas, todos os usuários teriam vantagens: os alunos teriam acesso quase imediato ao resultado de suas avaliações no mesmo lugar que sempre viram suas notas. Mais do que isso, teriam acesso a todos os relatórios sobre seu desempenho e da turma gerados automaticamente pelo Multiprova. Os professores não precisariam gerenciar turmas em dois sistemas diferentes e, cada vez que um aluno entrasse ou saísse da disciplina no meio do semestre sua situação seria automaticamente regularizada no Multiprova.

\subsection{Estratégia para integração}

Tendo em vista os benefícios advindos da cooperação entre os dois sistemas, as equipes de desenvolvimento do SIGAA e do Multiprova uniram-se em uma missão comum de implementação e consumo de um conjunto de serviços web. Tais serviços devem fornecer uma interface padronizada de acesso e estar de acordo com as atuais tendências tecnológicas de integração de sistemas. Nesse esforço comum, a equipe do SIGAA ficou responsável pela especificação e implementação dos serviços web, enquanto a equipe do Multiprova ficou responsável pela adaptação do sistema para utilização dos dados providos pelos novos serviços.

O grande desafio da solução é definir uma estratégia de integração entre os sistemas, permitindo reutilizar os componentes da camada de negócio já desenvolvidos no sistema de informação existente. Atualmente, a utilização do padrão de desenvolvimento em camadas (Buschmann, 1996) é muito comum, especialmente para os sistemas de informações web. Por esta razão, uma abordagem genérica que pode ser utilizada para integrar um sistema externo ao sistema web existente é a criação de um novo componente para fornecer os serviços que serão utilizados pelo sistema externo. Esse novo componente interage com a camada de regras de negócio já existente no sistema web, conforme apresentado na Figura 4. A grande vantagem desta abordagem é que ela permite adicionar novas capacidades ao sistema, enquanto reusa o núcleo do sistema já existente. 
Esse novo componente agrupa um conjunto de serviços RESTful, que nada mais são do que Web Services que seguem o estilo REST ${ }^{2}$. Atualmente, este estilo vem sendo bastante aceito e usado pela comunidade de desenvolvimento de software, pois os seus princípios fazem com que sua utilização tornem as aplicações mais simples e eficientes.

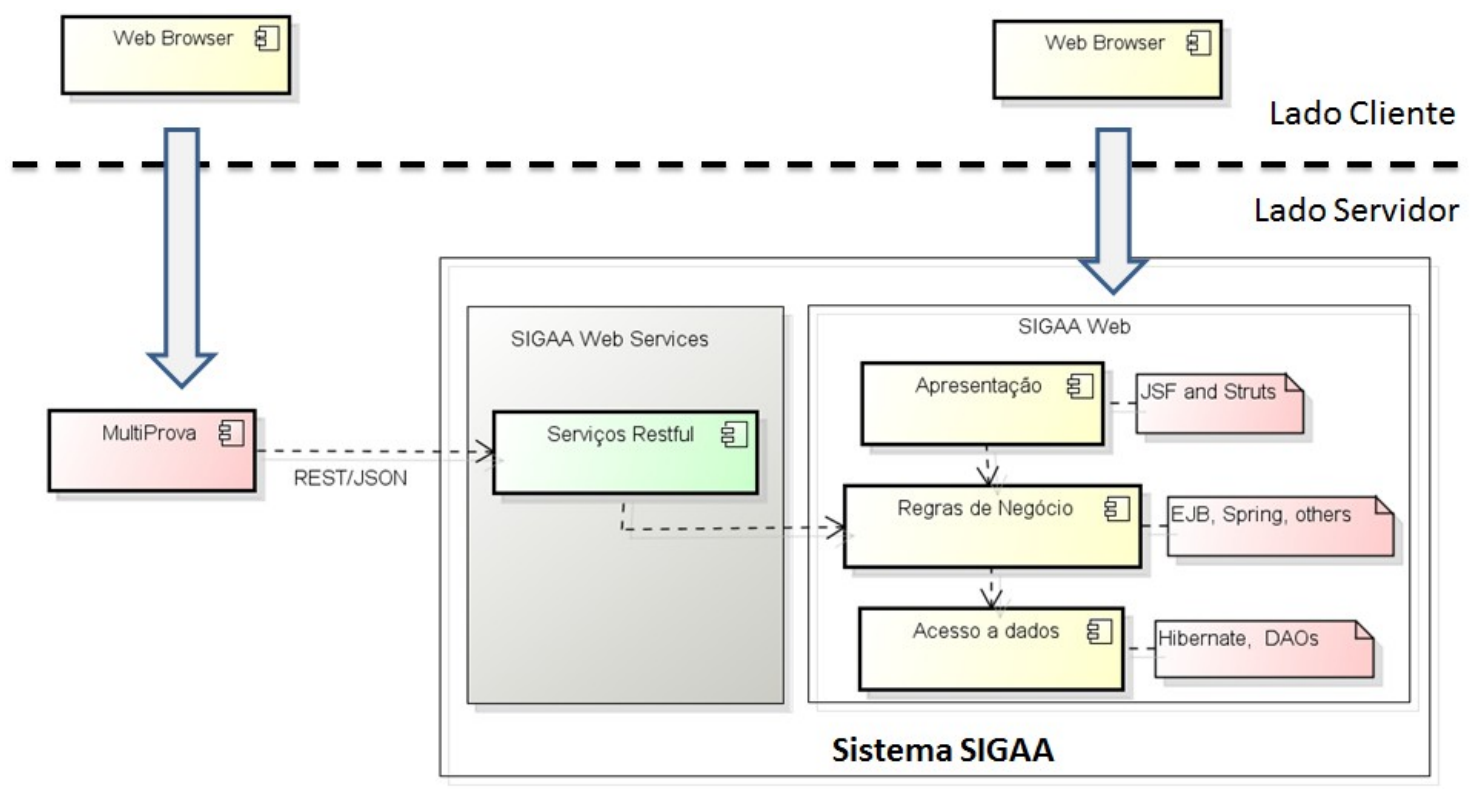

Figura 4 - Arquitetura da solução

Tendo-se definido a estratégia de integração dos dois sistemas, partiu-se para identificar e especificar o conjunto de serviços que precisam ser providos pelo SIGAA para atender as demandas atuais de funcionamento integrado do Multiprova. Como resultado desta análise, foram identificados dois grupos de serviços complementares: Serviços de consumo de dados e Serviços de atualização de dados.

\begin{tabular}{|l|l|l|l|}
\hline Nome & URL & Método & Descrição \\
\hline Autenticação & /usuario/login & GET & $\begin{array}{l}\text { Realiza o processo de autenticação do } \\
\text { usuário e retorna as credenciais para } \\
\text { acesso aos serviços }\end{array}$ \\
\hline $\begin{array}{l}\text { Detalhes do } \\
\text { usuário }\end{array}$ & /usuario/\{id\} & GET & $\begin{array}{l}\text { Retorna informações detalhadas do } \\
\text { usuário com identificador igual }\{\text { id }\}\end{array}$ \\
\hline $\begin{array}{l}\text { Lista de } \\
\text { Turmas }\end{array}$ & /turma & GET & $\begin{array}{l}\text { Para docente, retorna as turmas sob sua } \\
\text { responsabilidade, se pata discente as } \\
\text { turmas às quais está matriculado }\end{array}$ \\
\hline $\begin{array}{l}\text { Detalhes da } \\
\text { Turma }\end{array}$ & /turma/\{id\} & GET & $\begin{array}{l}\text { Retorna informações detalhadas da } \\
\text { turma com identificador igual a }\{\text { id }\}\end{array}$ \\
\hline
\end{tabular}

\footnotetext{
${ }^{2}$ REpresentational State Transfer (REST) é um termo originado de uma tese de doutorado sobre a web, escrita por Roy Fielding e refere-se a um conjunto de princípios de arquitetura relacionados ao desenvolvimento de serviços web (Fielding, 2000).
} 


\begin{tabular}{|l|l|l|l|}
\hline $\begin{array}{l}\text { Discentes da } \\
\text { Turma }\end{array}$ & $\begin{array}{l}\text { /discente?turma } \\
=\{\text { id }\}\end{array}$ & GET & $\begin{array}{l}\text { Retorna a lista dos discentes da turma } \\
\text { com identificador igual }\{\text { id }\}\end{array}$ \\
\hline $\begin{array}{l}\text { Docentes da } \\
\text { Turma }\end{array}$ & $\begin{array}{l}\text { /docente?turma } \\
=\{\text { id }\}\end{array}$ & GET & $\begin{array}{l}\text { Retorna a lista dos docentes da turma } \\
\text { com identificador igual }\{\text { id }\}\end{array}$ \\
\hline $\begin{array}{l}\text { Registro da } \\
\text { nota de } \\
\text { discente }\end{array}$ & /nota & POST & $\begin{array}{l}\text { Para docente, registra a nota de um } \\
\text { discente de uma turma em uma } \\
\text { determinada unidade }\end{array}$ \\
\hline $\begin{array}{l}\text { Registro da } \\
\text { nota da turma }\end{array}$ & /nota/\{turma $\}$ & POST & $\begin{array}{l}\text { Para docente, registra as notas dos } \\
\text { discentes da turma cujo id é igual a } \\
\text { turma }\} \text { em uma determinada unidade }\end{array}$ \\
\hline
\end{tabular}

Tabela 1 - Serviços REST disponibilizados pelo SIGAA

\section{Resultados esperados}

Os benefícios desta iniciativa podem ser analisados sob duas perspectivas distintas. Primeiramente, esta ação trará benefícios diretos de curto e médio prazo para a instituição, através da integração do Multiprova com o SIGAA. Esta integração facilitará a gestão do Multiprova ao mesmo tempo que trará uma maior confiabilidade nos dados utilizados, já que ele terá acesso direto e instantâneo aos dados institucionais, sem necessidade de replicação.

Além disso, um dos objetivos desta integração é levar o uso desta ferramenta para outros cursos da UFRN. Atualmente, a universidade possui 103 cursos de graduação, aos quais estão vinculados 4.490 docentes, atendendo a um total de 46.800 discentes. Por este motivo, vê-se um potencial enorme de a ferramenta beneficiar um grande número de discentes e docentes da instituição.

A relação entre estes dois sistemas pode ser comparada a uma relação de Mutualismo ${ }^{3}$ : o Multiprova se beneficia dos dados institucionais oficiais e, desta forma, oferece serviços de maior qualidade aos seus usuários; do outro lado, o SIGAA se fortalece, na medida em que incorpora uma solução de valor ao seu portfólio, oferencendo mais funcionalidades de apoio ao processo de ensino-aprendizagem.

Outro benefício da consolidação desta solução como ferramenta instituicional é a colaboração com a sustentabilidade. Com pouco esforço de desenvolvimento é possível prover uma interface de aplicação de provas eletrônicas, onde ficaria dispensado o uso de papel, acarretando em considerável economia de recursos e contribuindo para a preservação do meio ambiente.

A ferramenta Multiprova também pode ser usada para realização de registros detalhados das interações do discente com o sistema. Através da análise de tais registros é possível extrair informações extremamente relevantes para o entendimento do perfil dos alunos e tomada de decisões relacionadas às metodologias de ensino. Tais informações podem ser analisadas desde o momento que estes chegam à universidade até o momento de entrega desses alunos ao mercado de trabalho.

\footnotetext{
3 "Mutualismo define um tipo de interação entre duas espécies que se beneficiam reciprocamente da associação entre elas”. http://pt.wikipedia.org/wiki/Mutualismo_(biologia)
} 
Por fim, esta iniciativa estabelece um marco importante na cultura da instituição. Até então, todas as soluções de software instituicionais eram exclusivamente criadas e mantidas pela Superintenência de Informática. Soluções desenvolvidas por ações de docentes, discentes ou servidores técnico-administrativos, por mais interessantes que fossem, tornavam-se marginalizadas ou de uso restrito à unidade acadêmica que as criaram. Muitas iniciativas ficaram somente na ideia, já que não há formas de acesso oficial aos dados acadêmicos. As iniciativas que conseguiram ser desenvolvidas e se mantiveram em uso em suas unidades, demandam um esforço de administração maior que o necessário, já que o processo de atualização de dados institucionais se dá, na maioria dos casos, de maneira manual. Vale salientar que alguns dados acadêmicos sofrem alterações constantes ao longo do semestre, enquanto outros deixam de ser válidos a cada semestre. A descentralização das iniciativas de desenvolvimento de ferramentas de suporte às atividades acadêmicas cria um potencial de escala enorme para o surgimento de soluções inovadoras neste âmbito.

Espera-se que, em breve, outras soluções já existentes na instituição possam se integrar ao SIGAA e que, no médio prazo, sejam disponibilizados inúmeros serviços de acesso aos dados institucionais através da criação de uma plataforma de dados abertos. Inclusive, o desenvolvimento de plataforma deste tipo vem sendo uma prática comum em instituições públicas em todo o mundo ${ }^{4}$ (Anokwa, 2009) e, no Brasil, já existem vários casos similares acessíveis a partir do Portal Brasileiro de Dados Abertos ${ }^{5}$. Esta iniciativa criará um ambiente institucional que fomenta o desenvolvimento de um ecossistema de soluções acadêmicas em torno do SIGAA.

\section{Considerações Finais}

Do ponto de vista educacional, os esforços aqui descritos mostram como a tecnologia pode contribuir para o processo de ensino-aprendizagem, ajudando a vencer desafios, como o gerenciamento de turmas grandes e, ao mesmo tempo, oferecer ao aluno a possibilidade de ter um papel decisivo no seu processo individual de aprendizagem, através do rápido e representativo feedback dado pelo software Multiprova.

Do ponto de vistão da gestão do ensino, deve-se valorizar a iniciativa da UFRN em investir e apoiar o uso de tecnologias de informação, não apenas no gerenciamento de docentes e discentes, mas também, diretamente, na geração e aplicação de avaliações, permitindo uma maior eficiência.

Por fim, destaca-se, com a integração dos sistemas aqui tratados, a facilidade e a rapidez de acesso a importantes indicadores da qualidade do ensino na instituição utilizadora, através de relatórios estatísticos para alunos, professores e gestores. Esse fluxo de informações será fundamental para a identificação de novos caminhos na educação.

\section{Referências}

ALBRECHT, A. J. "Measuring Application Development Productivity,” Proceedings of the Joint SHARE, GUIDE, and IBM Application Development Symposium, Monterey, California, October 14-17, IBM Corporation (1979), pp. 83-92.

\footnotetext{
${ }^{4}$ https://www.data.gov/

5 http://dados.gov.br/
} 
ALTBACH, P.; REISBERG, L.; RUMBLEY, L. Trends in Global Higher Education: Tracking an Academic Revolution. A report prepared for the UNESCO 2009 World Conference on Higher Education. UNESCO, 2009 (Paris).

ANOKWA , Y.; HARTUNG , C.; BRUNETTE, W.; BORRIELLO, G.; LERER, A. "Open source data collection in the developing world." Computer 42.10 (2009): 9799.

BUSCHMANN, F.; MEUNIER, R.; ROHNERT, H.; SOMMERLAD, P.; STAL, M. (1996) Pattern-Oriented Software Architecture: A System of Patterns. John Wiley \& Sons, Inc., New York, NY, USA.

GIL, A. C. Didática do ensino superior. São Paulo: Editora Atlas, 2011.

ISO/IEC 20926:2009. Software and systems engineering - Software measurement IFPUG functional size measurement method, 2009. ISBN 9780580637551.

ISO/IEC 24570:2005. Software engineering - NESMA functional size measurement method version 2.1 - Definitions and counting guidelines for the application of Function Point Analysis, 2004. ISBN 0580456021.

KAMPFF, A.; ALVES, G. NetAula - Geração automática de avaliações. RENOTE Revista Novas Tecnologias na Educação, Rio Grande do Sul. v. 8, n.3, 2010.

FIELDING, R. T. Architectural Styles and the Design of Network-Based Software Architectures. Ph.D. Dissertation. University of California, Irvine. AAI9980887.

SPELLER, P., ROBL, F., MENGHEL, S. Desafios e perspectivas da educação superior brasileira para a próxima década. Brasília : UNESCO, CNE, MEC, 2012. 